\title{
DESIGN NO AMBIENTE HOSPITALAR: mesa para múltiplas atividades
}

\author{
Catherine Ribeiro Rosa \\ Universidade Federal de Santa Maria \\ catherine.r.rosa@gmail.com \\ Fabiane Vieira Romano \\ Universidade Federal de Santa Maria \\ fabiromano@gmail.com \\ Amara Holanda Battistel \\ Universidade Federal de Santa Maria \\ amarahb@gmail.com
}

Resumo: $O$ design tem a possibilidade de atuar para as mais diversas situações, pensando nisso, o presente trabalho tem como foco os pacientes do Centro de Tratamento da Criança e Adolescente com Câncer de Santa Maria. Através das análises e visitas ao local, observando o comportamento dos pacientes e demais frequentadores, foram identificadas várias oportunidades de melhoria do ambiente, como a falta de apoio para a realização de atividades cotidianas. $O$ objetivo do projeto, portanto, consiste em desenvolver uma mesa multitarefas adequada ao meio hospitalar. Com base nessa proposta realizaram-se pesquisas e análises, que definiram os requisitos projetuais para a definição da forma e funcionamento do produto final. Ao final do projeto foi confeccionado o modelo volumétrico e para sua validação o produto foi levado até o hospital para verificação dos feedbacks dos usuários e profissionais da saúde.

Palavras-chave: projeto de produto, design para ambiente hospitalar, mesa multifuncional.

Abstract: Product design can act for different situations. Thinking about this, this paper focuses on patients of the Treatment Center for Children and Adolescents with Cancer of Santa Maria. Through several analysis and site visits, observing the behavior of patients and other attendees, several opportunities to improve the environment were perceived, such as a lack of support for performing daily activities. The project's goal, therefore, is to develop a multi-task table appropriate to hospital setting. Based on this proposal, research and analysis were held, which defined the design requirements of form and function for the final product. At the end a 
volumetric model was made and to validate it, the product was taken to the hospital to check on feedbacks from users and health professionals.

Keywords: product design, design for hospital environment, multifunctional table.

\section{INTRODUÇÃO}

Segundo Margolin (2007, p. 4, tradução nossa) "designers estão certamente entre aqueles cujas contribuições positivas são essenciais para a construção de um mundo mais humano", através dessa atividade apresentam-se diversas possibilidades de explorar as necessidades do usuário e sua resposta aos produtos e serviços disponibilizados, e se pode agir para o benefício das pessoas com projetos que melhoram a interação do indivíduo com o espaço e situações que o cercam.

Em grande parte das vezes em que adoecemos temos que adaptar nossas atividades do dia a dia para tratar da enfermidade, moldando nossa forma de lidar com os acontecimentos a fim de nos adequarmos às exigências do tratamento da doença. Supondo que haja a necessidade de internação, a rotina hospitalar pode atingir diretamente os pacientes, pois é necessário habituarem-se a um mundo desconhecido, com situações, relações, rotinas e atividades diferentes as que se está acostumado.

No Brasil estima-se que 12 a 13 mil crianças sejam diagnosticadas com câncer anualmente (GUIA INFANTIL, 2013); e, o tratamento do câncer, em específico, "tem como característica o fato de ser prolongado, demandando um tempo considerável de hospitalização e expondo a criança a procedimentos invasivos e desagradáveis, tanto física quanto emocionalmente" (MOTTA; ENUMO, 2004, p.194). Deste modo, é importante que se disponha de um ambiente que promova na medida do possível bem estar a estes pacientes, colaborando para o sucesso do tratamento e para a continuidade do desenvolvimento da criança ou adolescente.

"Na infância, um episódio de doença pode significar um trauma, bem como um atraso ou mesmo interrupção no processo de crescimento e desenvolvimento" (BORTOLOTE; BRÊTAS, 2008, p.423), porém esses aspectos podem ser diminuídos através de soluções que contribuam para o conforto e o alívio, transformando o espaço onde permanecem em um aliado para a cura. "O ambiente deve incentivar a saúde e deve ser organizado de maneira que atenda melhor às necessidades dos pacientes" (SOARES; ZAMBERLAN, 2001 apud BEGNIS; CARVALHO, 2006, p.111) e essas necessidades não são apenas às referentes aos tratamentos médicos, pois crianças e adolescentes em particular possuem necessidade de brincar, aprender, interagir, entre outros, e o ambiente tem que disponibilizar meios em que esses indivíduos cresçam da melhor maneira. É importante, principalmente durante a fase de desenvolvimento, que se proporcione as condições necessárias para que o paciente que necessita de internação permaneça, embora que de forma mais limitada, ligado ao mundo e ao dia a dia que conhece.

Dentro do ambiente hospitalar é possível que as mais distintas profissões ajam para tornar menores os aspectos invasivos na vivência da criança e do adolescente 
através de soluções simples que podem contribuir para a comodidade, então porque não incluir o design nessa tarefa?

Esse trabalho desenvolveu-se no Centro de Tratamento da Criança e do Adolescente com Câncer (CTCriaC), localizado no Hospital Universitário de Santa Maria (HUSM), dentro do campus da Universidade Federal de Santa Maria (UFSM), em parceria com a terapia ocupacional, com intuito de levar o design para dentro do hospital projetando um produto adequado para o meio hospitalar para a utilização pelos pacientes que vivenciam a internação, auxiliando em suas atividades diárias e relacionamento com o ambiente em que estão acomodados.

Para desenvolvimento do projeto o método utilizado tem como base Bonsiepe (1984) e também a metodologia que vem sendo desenvolvida pela Projetar Empresa Júnior de Desenho Industrial (MATTE et al., 2013), por seu caráter cíclico e de flexibilidade, atendendo cada projeto em suas particularidades. Combinando e adaptando esses dois métodos, chegou-se ao processo de projeto realizado neste trabalho (Figura 1).

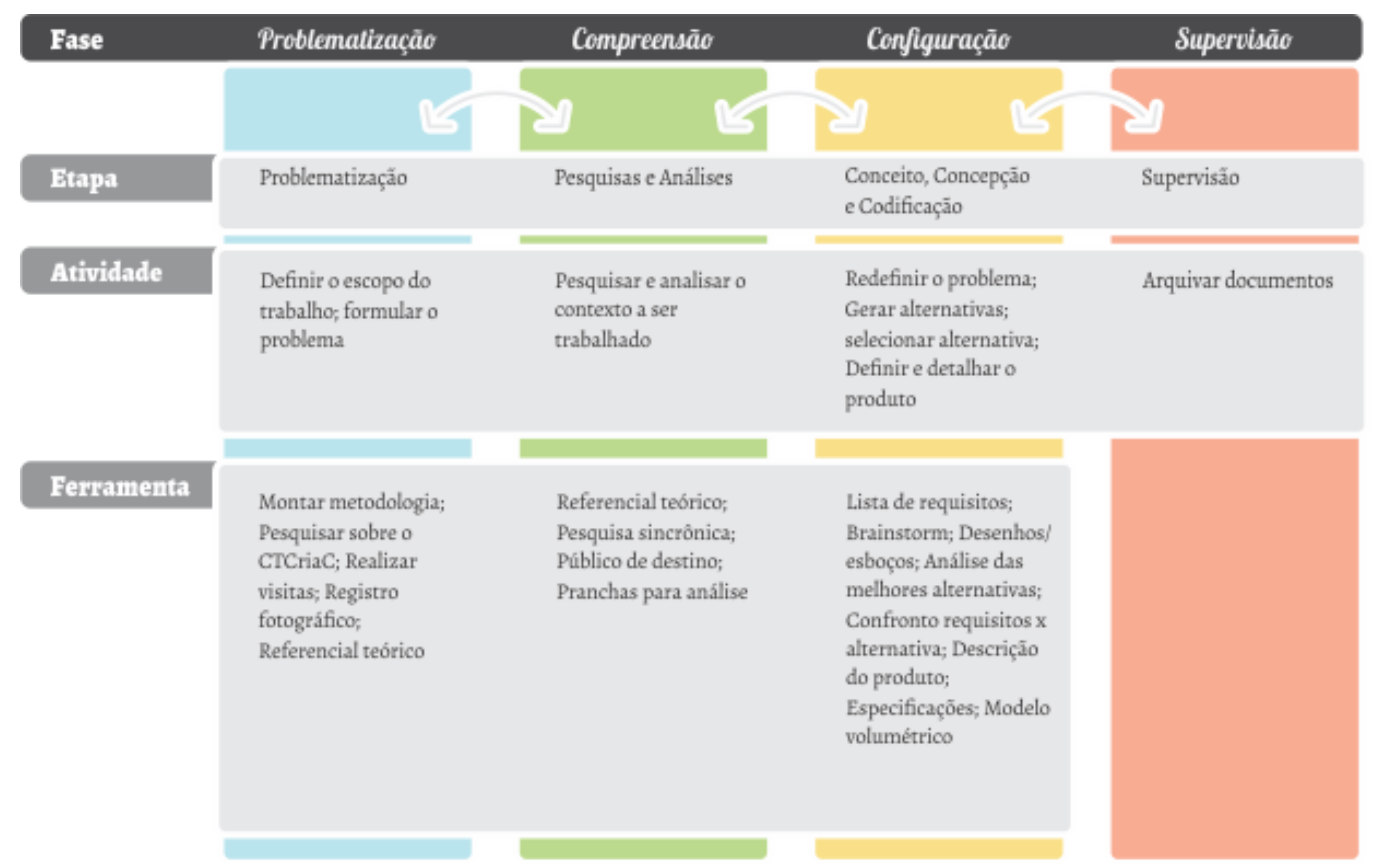

Figura 1 - Figura da Metodologia. Fonte: Elaborado pelo autor.

\section{O AMBIENTE}

O CTCriaC é a unidade de internação de crianças e adultos jovens ( 0 a 20 anos) com leucemias, tumores sólidos e distúrbios hematológicos que realiza assistência no diagnóstico, tratamento e manutenção, contando com profissionais de enfermagem, médicos, psicólogos, nutricionistas, fisioterapeutas e terapeutas ocupacionais e da assistência a mais de 450 pacientes por ano. Sua estrutura física segue aos padrões hospitalares, contando também com a brinquedoteca como ajuda para o trabalho de humanização, disponibilizando aos seus pacientes um ambiente de diversão.

Os quartos onde permanecem internados (Figura 2 e Figura 3), porém, não apresentam qualquer apelo ou característica acolhedora que possam deixar seus habitantes mais relaxados e confortáveis e a brinquedoteca não pode estar disponível 
a eles em tempo integral, visto que conta com os profissionais da saúde e voluntários para supervisão.

Atualmente esse ambiente dispõe de poucos recursos de recreação e seu mobiliário tem sua utilização bastante restrita, devido à rotina de medicamentos e procedimentos efetuados pelos profissionais da saúde.

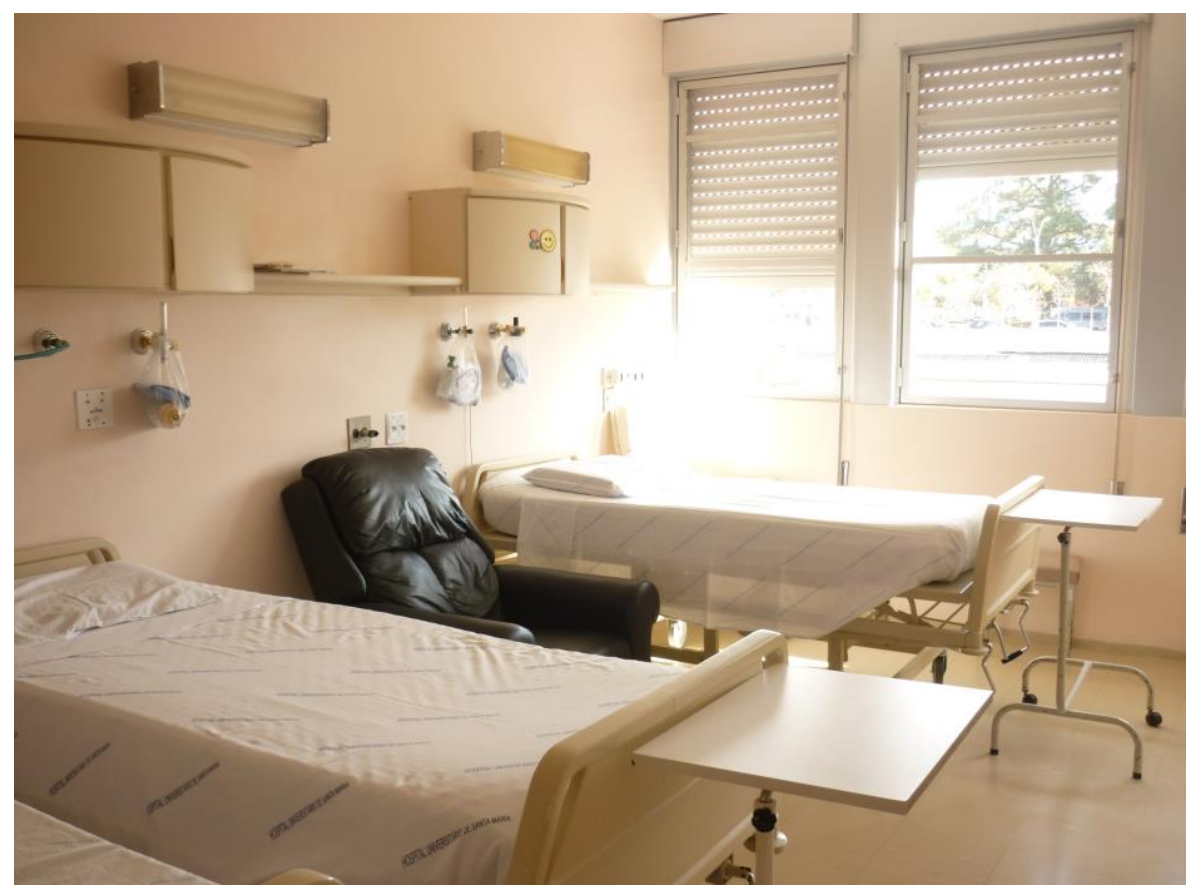

Figura 2 - Foto dos quartos do CTCriaC. Fonte: Elaborado pelo autor.

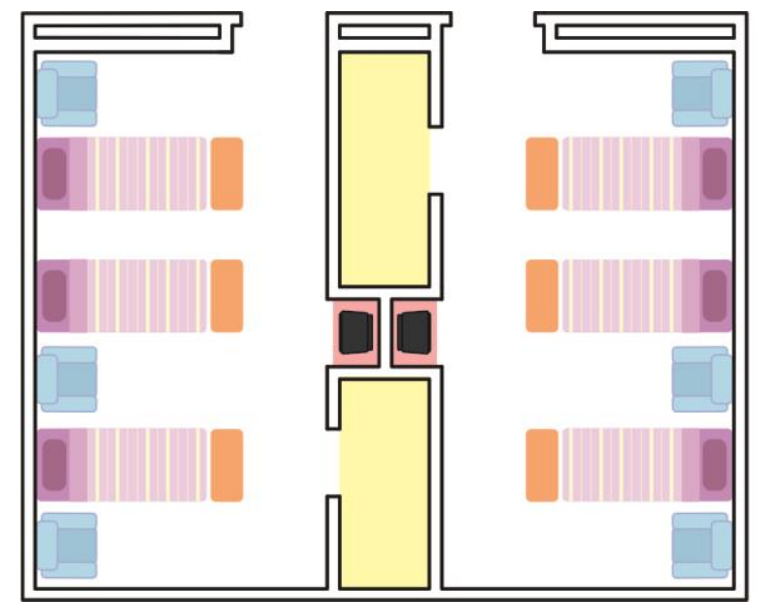

Televisão

Pias

Banheiros

Cadeiras dos cudadores

Camas

Mesas

Figura 3 - Planta baixa dos quartos do CTCriaC. Fonte: Elaborado pelo autor.

Com certeza o espaço apresenta potencial para ser melhorado de forma que possa se tornar um ambiente acolhedor para se ficar, recebendo seus pacientes de maneira aconchegante e se transformando em um lugar interessante, mas existem particularidades e dentre essas, algumas restrições específicas de ambientes hospitalares que precisam ser respeitadas, como por exemplo os materiais a serem usados nos produtos. 


\section{O PROJETO}

Utilizando as 3 perguntas de Gui Bonsiepe (1984) - O que? Por quê? E como? é possível definir o problema a ser resolvido como: desenhar um suporte para múltiplas atividades que se adeque ao meio hospitalar para atender internados (Figura 4).

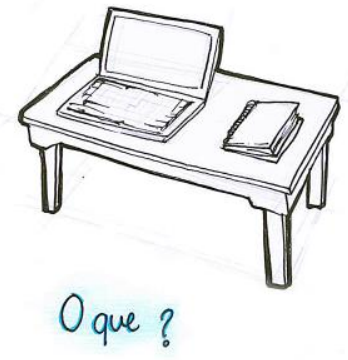

Suporte adaptárel em ambiehte hospitalar. Suporte para notehooks cadernos, brinquedos, livros $e$ demais atividades, que se adeque ao meio hospitalar.

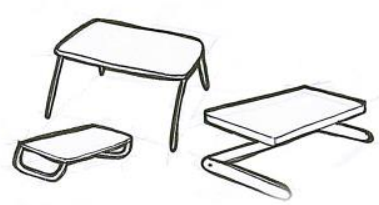

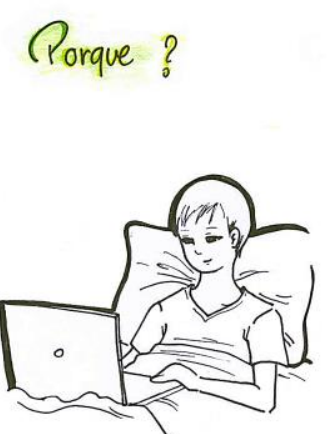

Desenvolvimento de trahalho de conclusăo de curso que proponha um produto que auxilie os pacientes $e$ seus acompanhantes do cterial no HUSM.

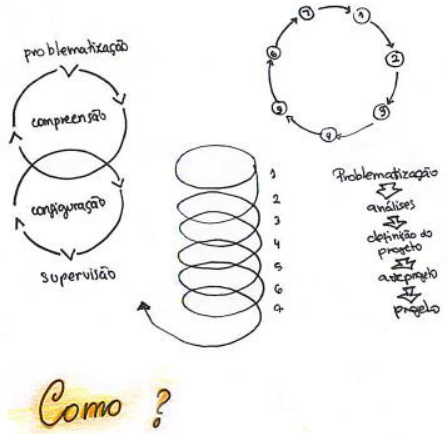

Através da melodologia desenuduida pela Projetar Empresa fúnior de Desenho Indusdrial e Bonsiepe.

Figura 4 - Definição do problema. Fonte: Elaborado pelo autor.

O produto tem como finalidade proporcionar aos pacientes recreação e diferentes formas de utilização, desempenhando seu papel sem interferir no funcionamento da rotina hospitalar, e adequando-se ao ambiente não somente ao respeitar o andamento das atividades locais, como também configurando-se com materiais e formas aceitáveis nesse meio.

Tendo em vista que o produto a ser produzido não possui uma categoria específica, e que deve permitir múltiplas atividades, as pesquisas e análises foram realizadas a partir de suas funções a serem desempenhadas, classificadas em três principais: brincar, armazenar e dar apoio. Também foram reconhecidos produtos semelhantes ao objeto a ser desenvolvido que desempenhassem atividades afins, incluiu-se: mesas para crianças, mesas portáteis e mesas para notebooks, pois essas mostram uma proposta mais similar ao que se pretende alcançar com o projeto em desenvolvimento. Com essa estratégia foi possível conhecer soluções que existem e estudar possibilidades para o produto a ser desenvolvido (Figura 5), reconhecendo sistemas, padrões, estruturas, formas, encaixes, etc. 


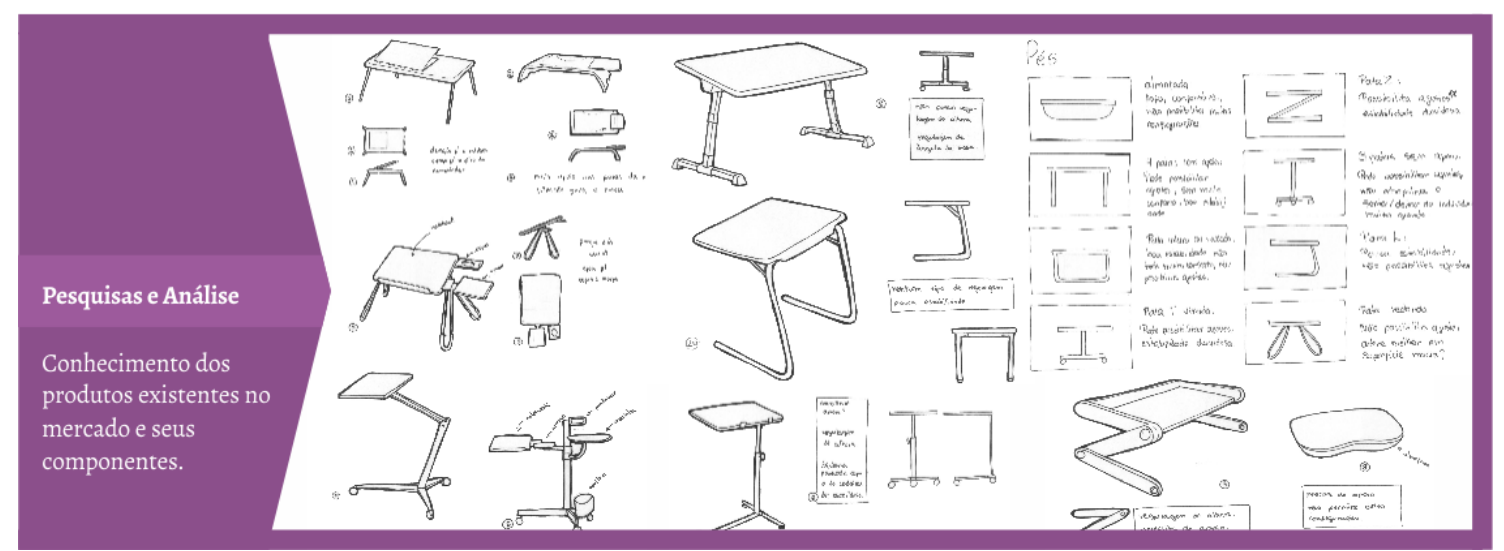

Figura 5 - Síntese das análises e pesquisas. Fonte: Elaborado pelo autor.

Além de conhecer os produtos existentes, conhecer o cliente final é essencial para qualquer projeto, e, embora este trabalho tivesse como público específico os pacientes do CTCriaC, manteve-se a possibilidade de utilização mais ampla, ou seja, um produto adequado ao meio hospitalar mas que possa ser usado também em outras situações. Por isso, ficou definido como público alvo crianças e adolescentes de 3 a 20 anos, porém mantendo sempre a atenção para com as restrições que o local de aplicação exige.

A utilização de painéis nessa etapa do trabalho foi importante para a compreensão de quem é o usuário, como ele vive - atividades comuns ao seu dia a dia -, e o ambiente ao qual o produto irá ser designado. Para a construção desse painel optou-se por excluir atividades seletas dos pacientes com câncer e tratar suas características como as de crianças e adolescentes em geral, já que o produto tem como proposta resgatar essas atividades típicas do cotidiano desses indivíduos e tentar trazê-las para dentro do ambiente hospitalar (Figura 6).
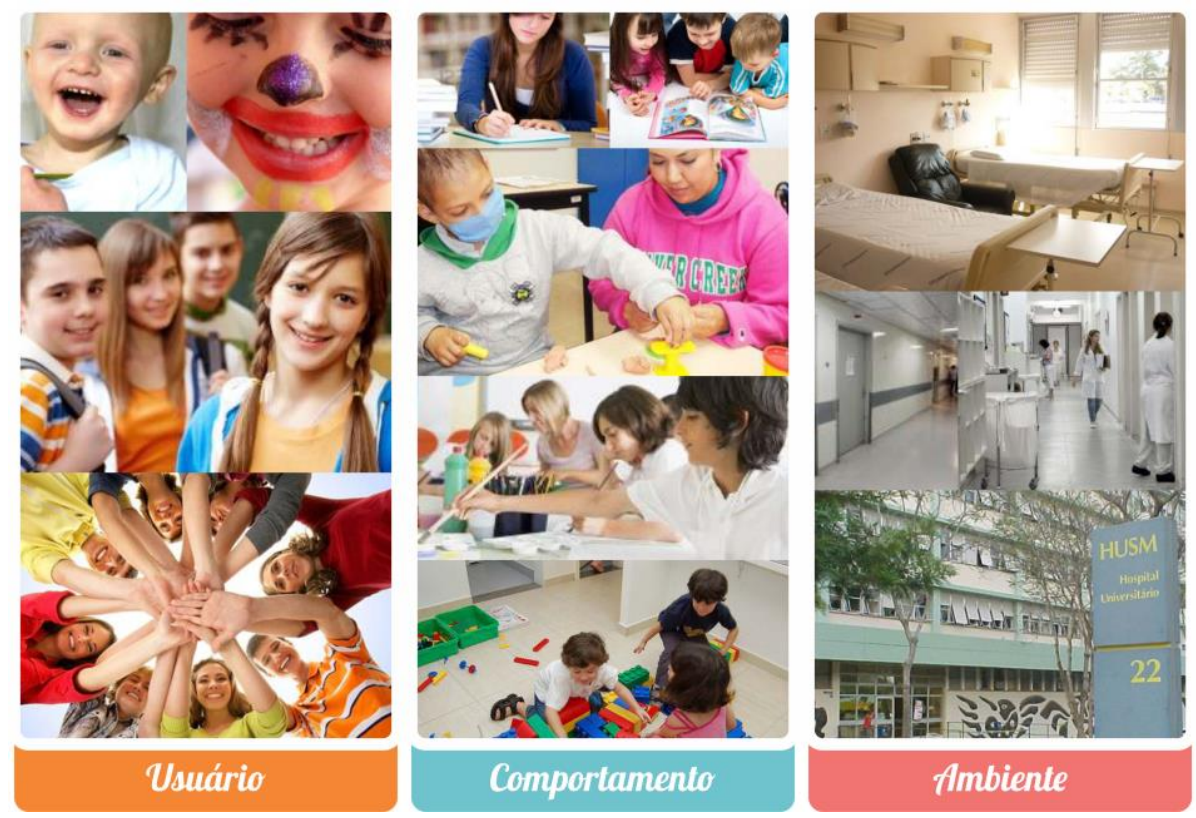

Figura 6 - Painel do Usuário. Fonte: Elaborado pelo autor.

A partir das análises realizadas, reconhecimento do público e do ambiente para o qual o projeto se desenvolveu, a conceituação foi iniciada escolhendo 3 palavras que, de certa forma, englobassem todas as expectativas com relação ao produto a ser 
desenvolvido. São elas: emoção, conforto e adaptação (Figura 7). A emoção corresponde ao objetivo de que o produto se relacione de forma positiva com o usuário, dando a ele boas sensações e uma relação mais amigável com o local de permanência. $\mathrm{O}$ conforto corresponde ao bem-estar, à comodidade e ao aconchego. Suprir a necessidade de tornar o usuário confortável independente do lugar em que se encontra, disponibilizando meios para que o usuário exerça suas atividades de forma efetiva. Por último a adaptação, acomodação, que corresponde à necessidade do produto se adequar a um ambiente restrito e também configurar-se para atender aos desejos do usuário. O produto deverá adaptar-se ao meio e as ações que o ambiente e o usuário demandam.

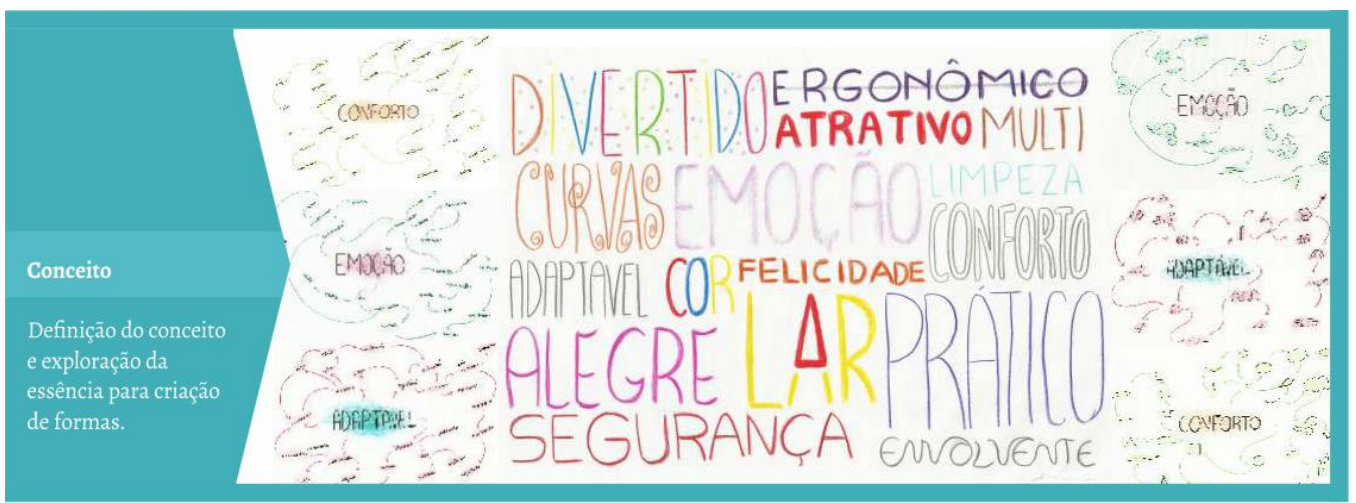

Figura 7 - Síntese da conceituação. Fonte: Elaborado pelo autor.

A partir de todas as informações coletadas foi possível realizar a definição de requisitos e a redefinição do problema passando-se então à geração de alternativas, agora com uma visão mais focada e detalhada do que se esperava do projeto do produto (Quadro 1 e 2). Os requisitos são utilizados para "orientar o processo projetual em relação às metas a serem atingidas" (BONSIEPE, 1984). Segundo Bonsiepe (1984) "Convém formular cada requerimento separadamente, e utilizar uma forma comum (frases positivas, sem negação". De tal modo, primeiramente os requisitos foram listados a partir de cada item da do produto que pretende-se construir.

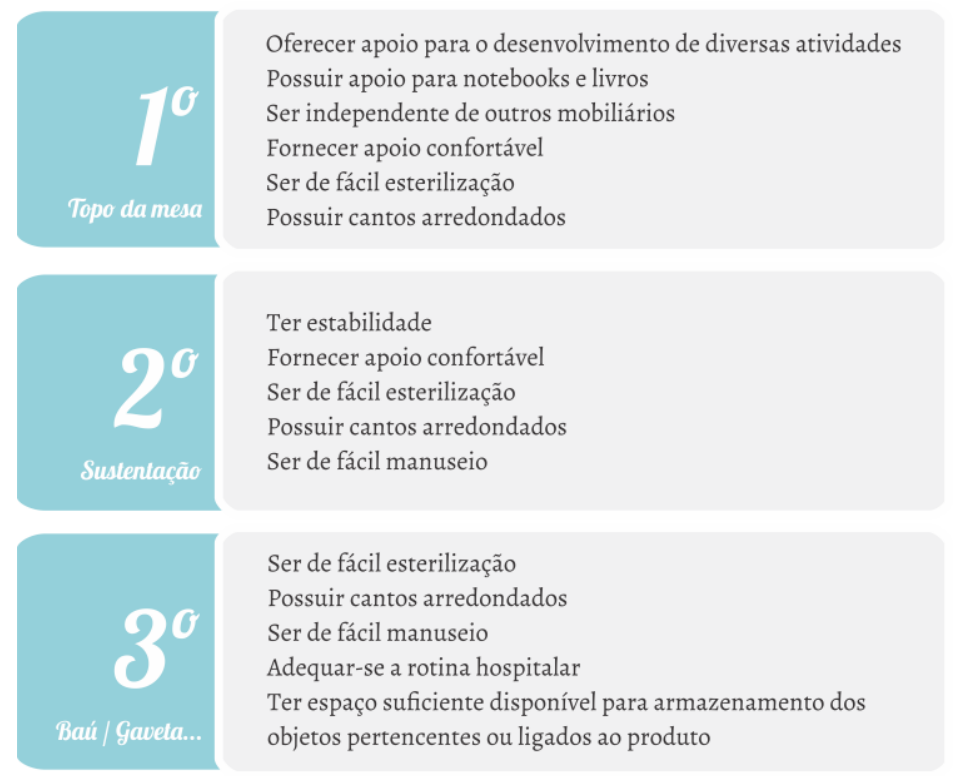

Quadro 1 - Requisitos por item. Fonte: Elaborado pelo autor. 
Tendo listadas as condições de cada item é mais fácil a visualização do produto como um todo, e a partir dos assuntos já abordados e acrescentando itens que julgouse em falta foi desenvolvido um resumo dos requisitos do produto, tendo organizado o que se espera dele, o que ele não poderá ser e como ele deve ser (Quadro 2).

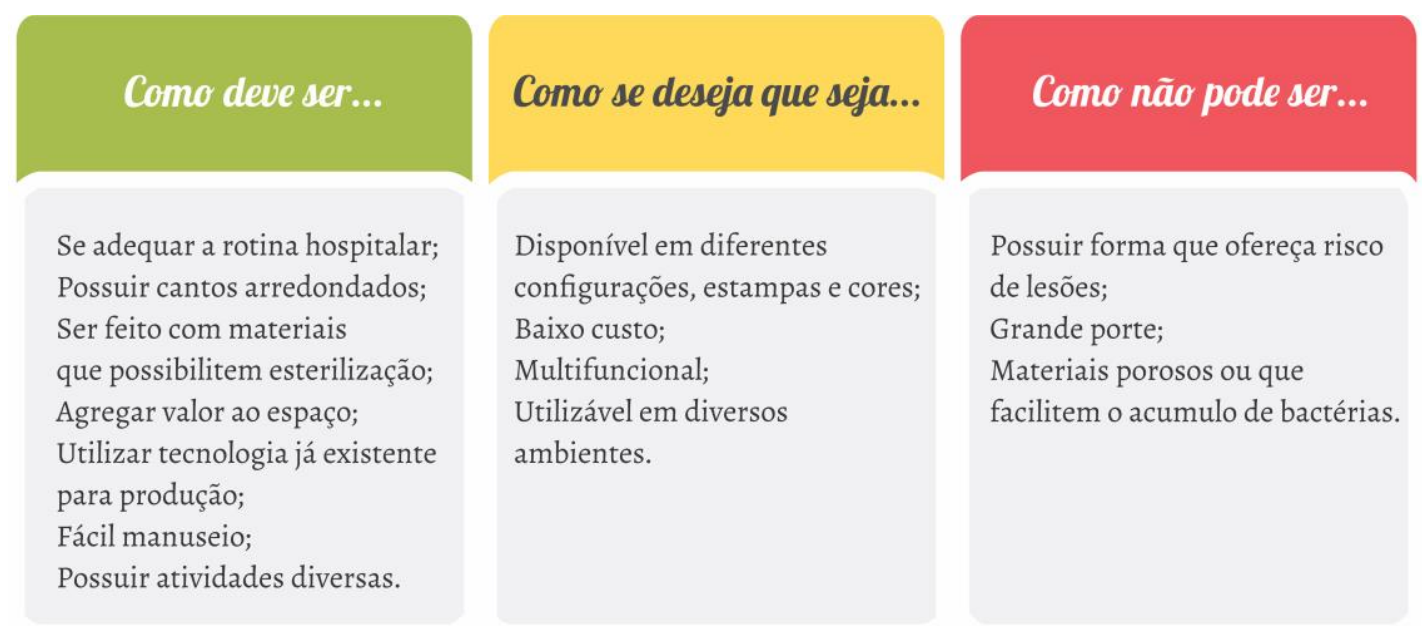

Quadro 2 - Requisitos. Fonte: Elaborado pelo autor.

Existem diversas ferramentas que auxiliam na geração de alternativas, a fim de torná-la mais produtiva, para esse trabalho escolheu-se o brainstorming, que consiste em relatar todas as ideias que forem pensadas, através de frases, palavras, desenhos ou conversas. Foram utilizados dois tipos de brainstorming, o brainstorming ortodoxo e o brainstorming destrutivo/ construtivo. No primeiro as ideias são colocadas sem censura, "com explícita proibição de formular observações críticas" (BONSIEPE, 1984), o segundo vem para tornar mais objetivas as ideias lançadas durante o primeiro brainstorming, "serve para filtrar os pontos fracos das propostas da 1a fase, e concentrar sua atenção à sua solução" (BONSIEPE, 1984).

Além dessa do brainstorming foram utilizados mocapes para teste e caixas morfológicas aliadas aos rascunhos, retornando as ideias e modificando-as quantas vezes necessário até que fosse possível a identificação de um esboço que se adequasse aos requisitos e aos meios de produção (Figura 8).

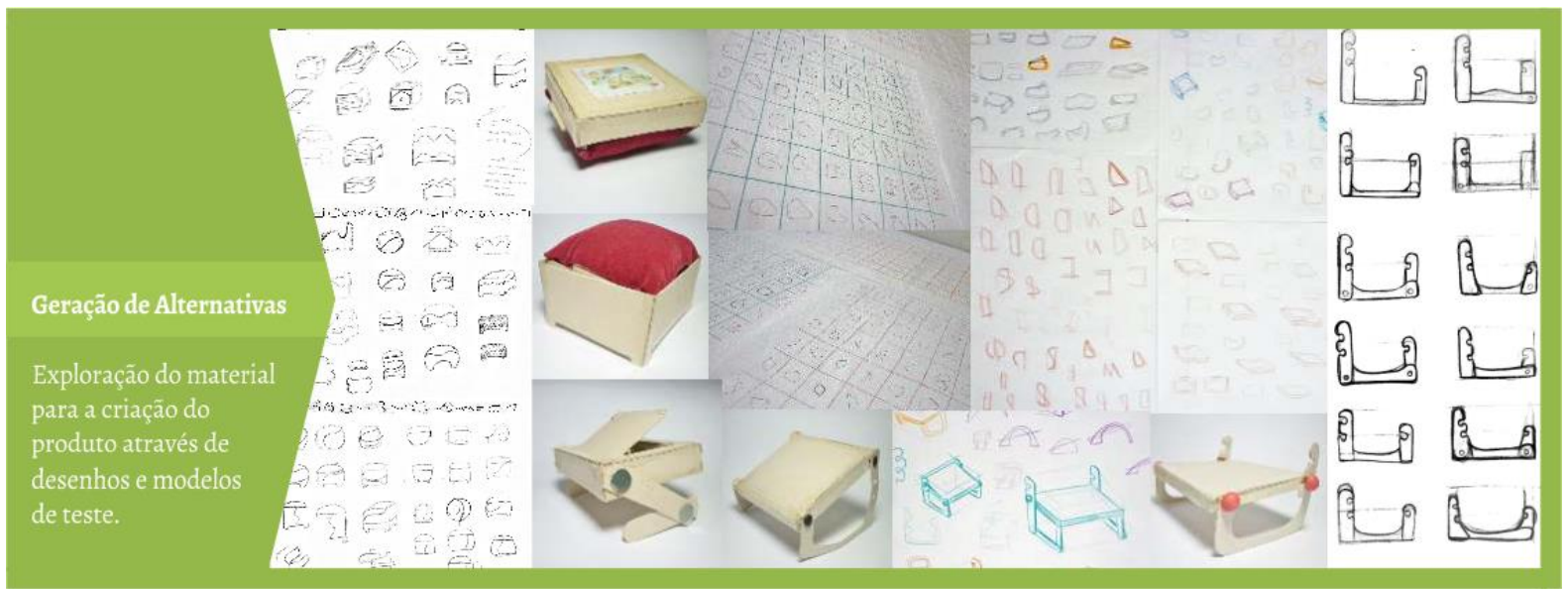

Figura 8 - Síntese da geração de alternativas. Fonte: Elaborado pelo autor. 
Tendo selecionada a alternativa mais apropriada, essa passou pelo refinamento necessário e pelas especificações, sendo então escolhidos materiais, cores, acabamentos e formas de fabricação (Figura 9).

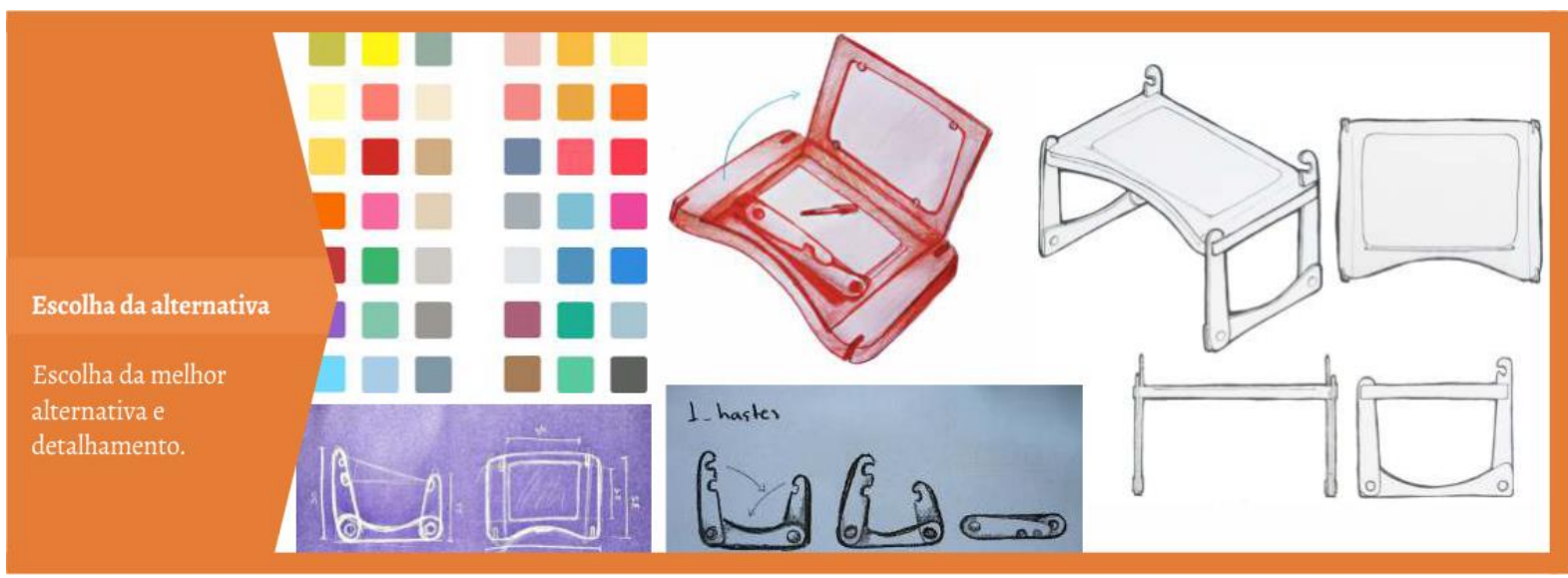

Figura 9 - Síntese da escolha de alternativa e especificação. Fonte: Elaborado pelo autor.

\section{O RESULTADO}

Como produto final foi desenvolvido um suporte para múltiplas atividades que se assemelha a uma mesinha, podendo ser utilizado para estudar, ler, brincar, desenhar, comer, apoio para notebooks, entre outros (Figura 10).
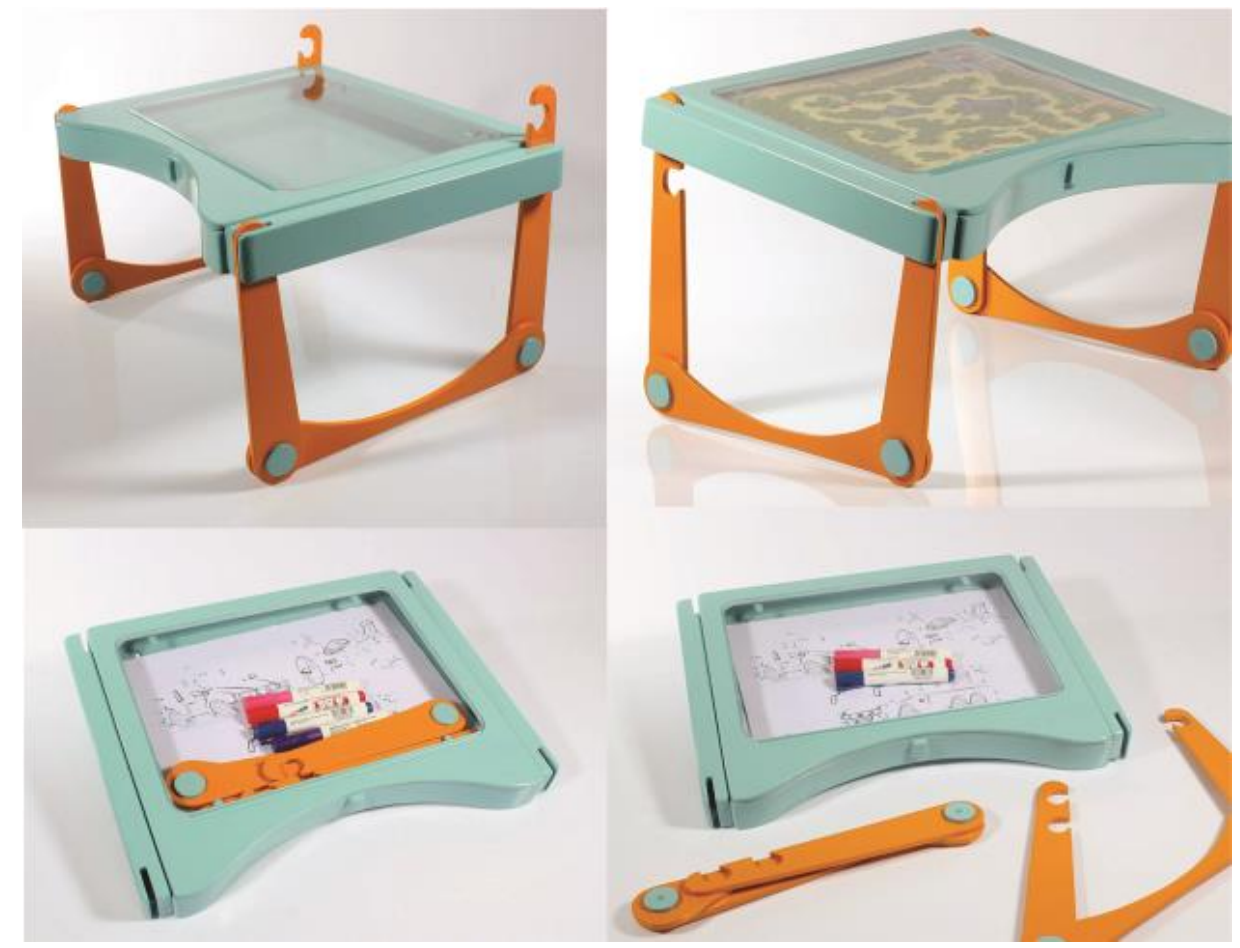

Figura 10 -Produto Final. Fonte: Elaborado pelo autor.

As hastes são retráteis e de fácil manuseio, o tampo possui um encaixe para folhas de atividades ilustradas que se dá a partir de prendedores na parte interna para segurar as páginas e conta com uma tela transparente para que os usuários possam 
riscar e limpar com facilidade, descartando também o uso do papel - que não é muito aconselhado dentro de unidades de internação.

Outra grande preocupação era o fluxo do hospital que deve estar sempre funcionando para melhor atender ao paciente, não podendo portanto conter objetos obstruindo o caminho dentro dos quartos, caso haja a necessidade de deslocamento de equipamentos ou trânsito de médicos e demais funcionários. Para que o produto não atrapalhe na rotina do hospital, na parte traseira existem encaixes para ganchos, assim, quando não estiver sendo utilizada a mesa poderá virar um quadro, podendo expor desenhos das crianças, informativos sobre o hospital, recados, etc. Possui também a possibilidade de ser guardado, sendo desmontável, e para que nada ocupe espaço no hospital as canetas, jogos e hastes da mesa podem ser guardados em seu interior, evitando transtornos e perdas de material. A possibilidade de armazenamento também auxilia caso o objeto necessite ser transportado.

Após levar o produto até o hospital, o feedback recebido foi bastante positivo entre crianças, adolescentes, terapeutas ocupacionais, médicos e enfermeiros que estavam no local e puderam ver o produto em funcionamento. Na chegada ao local uma das crianças internadas estava realizando seus deveres escolares em uma prancheta, com as costas inclinadas em posição desconfortável e não adequada para a realização da tarefa. As crianças em tratamento tendem a se sentirem fracas e o desgaste físico causado pela falta de um equipamento adequado as prejudica. Assim, foi oferecida à menina a mesa para que ela fizesse suas atividades e sua primeira declaração foi: "ficou melhor, agora posso apoiar a mão...". Notou-se também uma melhora na postura com a utilização da mesa e além dessas contribuições o produto foi julgado como visualmente agradável (Figura 11). O produto foi testado também em outra paciente com mais idade e uma criança com a idade mínima para o uso.

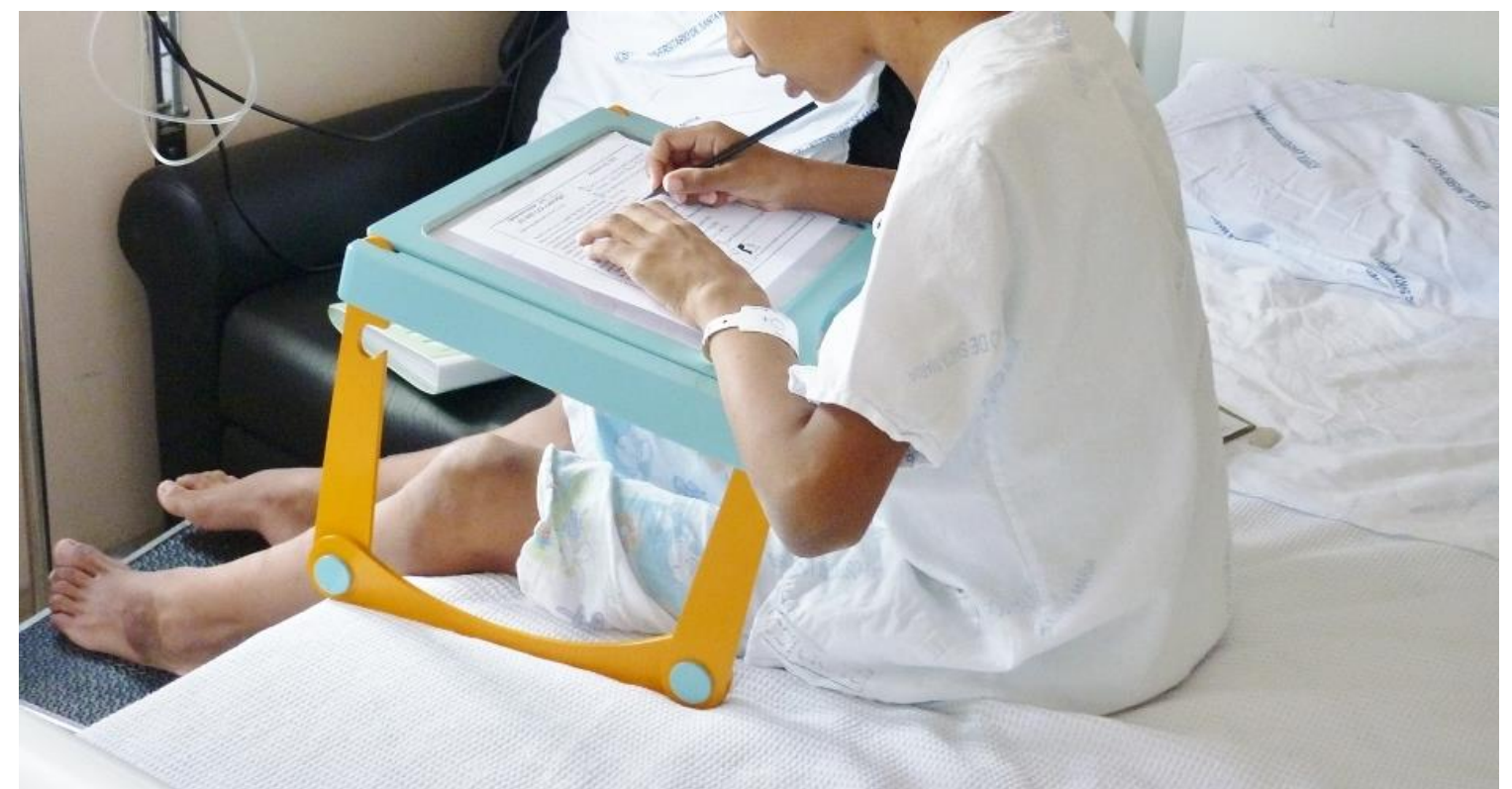

Figura 11 - Paciente utilizando o produto (10 anos). Fonte: Elaborado pelo autor. 


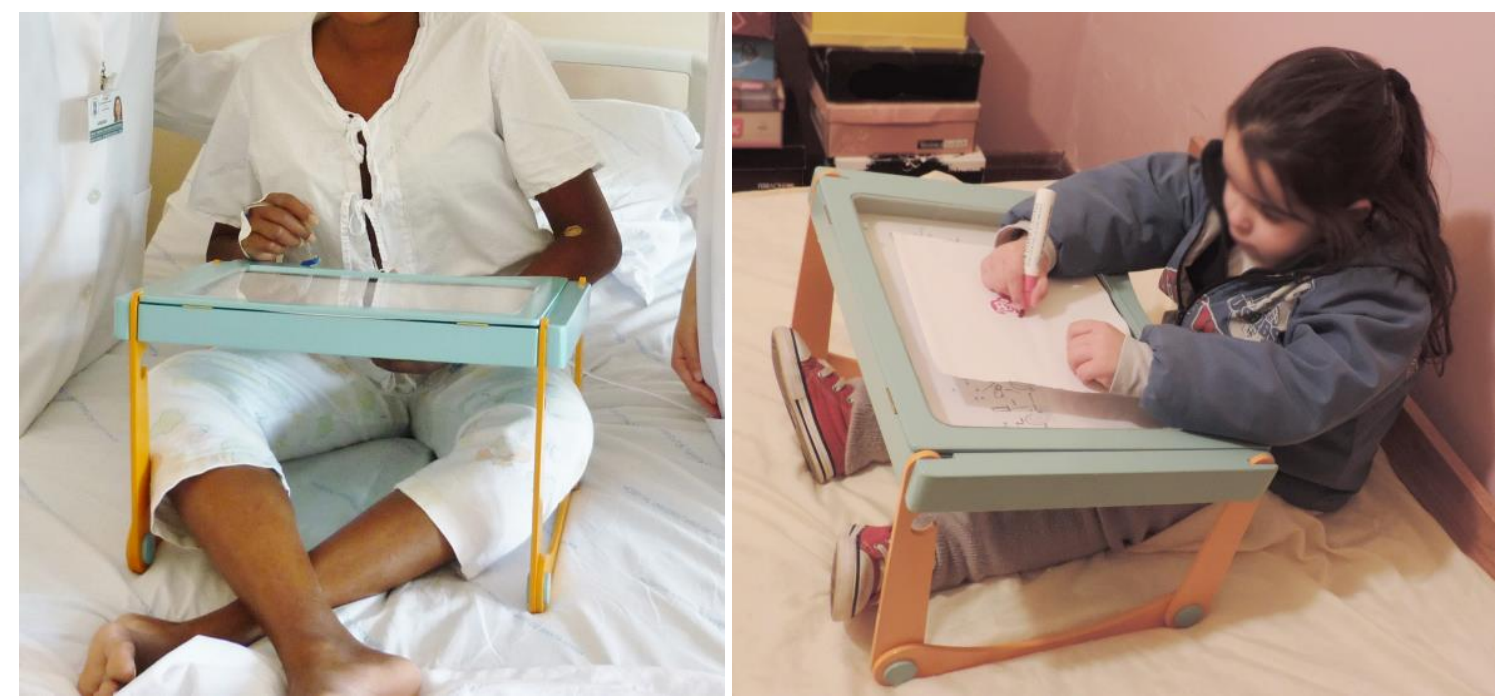

Figura 12 - Criança e paciente utilizando o produto (3 e 20 anos, respectivamente). Fonte: Elaborado pelo autor.

Com o protótipo pôde-se confirmar que o produto apresenta em sua configuração os conceitos que deram início a geração: o conforto, a adaptação e a emoção. A oportunidade de teste do produto com o público de destino e no local para o qual foi planejado possibilitou a validação do projeto, com isso verificando se a proposta foi satisfatória e se o produto se comportou da maneira desejada e obtendo uma avaliação positiva. Sua forma e cores levam uma característica mais alegre e infantil aos quartos, quebrando as cores padrões do hospital. A praticidade que apresentou trouxe aos pacientes um conforto maior, podendo atender também aos pais e aos profissionais da saúde, como por exemplo, os terapeutas ocupacionais, que realizam atividades com as crianças e adolescentes em internação, mas não possuíam até então um apoio adequado. A mesa além de atender seu propósito apresenta potencial para auxiliar dentro do hospital e também em outros ambientes, pois não restringe seu uso e adapta-se a diferentes formas de utilização.

\section{CONCLUSÃO}

Através desse trabalho foi possível compreender o universo que envolve a doença e as rotinas do meio hospitalar, entendendo suas limitações e cuidados, projetando de maneira responsável para que essas características fossem respeitadas. O tratamento deve ser pensado como um todo, englobando medicamentos, ambiente, atividades e relacionamentos desenvolvidos durante esse período.

A interdisciplinaridade foi essencial para o desenvolvimento desse trabalho. Sem o contato com a terapia ocupacional, enfermagem, arquitetura e outras áreas o projeto seria muito dificultado. É importante lembrar que o design não está sozinho buscando soluções para as pessoas, mas temos as mais diversas áreas trabalhando para alcançarmos melhorias. Podemos obter resultados mais significativos se pudermos unir as competências e conhecimentos.

O projeto atingiu o objetivo de ser adequado ao ambiente hospitalar e recebeu boa resposta dos usuários, e embora o público principal do trabalho fossem os pacientes do CTCriaC o produto não possui contra indicações para ser utilizado em outros ambientes. 
Existem diversas possibilidades dentro do ambiente hospitalar para que 0 design possa atuar, espera-se que mais ações destinadas a esse universo sejam produzidas futuramente.

Por fim, desenvolvendo esse trabalho foi possível enxergar mais claramente o alcance do design e a importância que pode atingir para a modificação de um ambiente ou relações do usuário com suas atividades. Relembrando as palavras de Margolin (2007, tradução nossa), "designers estão certamente entre aqueles cujas contribuições positivas são essenciais para a construção de um mundo mais humano", espera-se que esse projeto, quando implementado, seja uma dessas contribuições.

\section{REFERÊNCIAS}

BEGNIS, G. J.; CARVALHO, A. M. Brincar em unidades de atendimento pediátrico: Aplicações e perspectivas. Psicologia em estudo, Maringá, v. 11, n. 1, p. 109-117, jan./abr. 2006. Disponível em: <http://www.scielo.br/pdf/pe/v11n1/v11n1a13>. Acesso em: 23 maio 2013.

BONSIEPE, G. Metodologia experimental/Desenho industrial. Brasília: CNPq/Coordenação Editorial, 1984.

BORTOLOTE, G. S; BRÊTAS, J. R. S. O ambiente estimulador ao desenvolvimento da criança hospitalizada. Rev. Escola de Enfermagem, São Paulo, 2008. Disponível em: <http://www.scielo.br/pdf/reeusp/v42n3/v42n3a01.pdf> Acesso em: 21 jul. 2013.

GUIA INFANTIL. O câncer infantil. Disponível em: <http://br.guiainfantil.com/cancerinfantil.html>. Acesso em: jul. 2013.

MARGOLIN, V. Design, the Future and the Human Spirit. Design Issues, v. 23, n. 3, verão 2007. Disponível em: <http://www.mitpressjournals.org/doi/pdf/10.1162 /desi.2007.23.3.4>. Acesso em: 03 jun. 2013.

MATTE, V. A; ROMANO, F. V; LICHT, M. C; COSTA, M. L. Método flexível para a atividade projetual do design: uma proposta de jogo. In: Congresso Brasileiro de Gestão de Desenvolvimento de Produtos, 2013, Natal, RN. Anais. Natal: 9o CBGDP, 2013.

MOTTA, A. B; ENUMO, S. R. F. Câncer Infantil: Uma proposta de avaliação das estratégias de enfrentamento da hospitalização. Estudos de Psicologia, Campinas, v.21, n.3, p.193-202, setembro/dezembro 2004. Disponível em: <http://www. oncopediatria.org.br/cancer-infantil-uma-proposta-de-avaliacao-das-estrategias-de>. Acesso em: 09 maio 2013. 